\title{
A PERCEPÇÃO DO CONSUMIDOR SOBRE AS IMAGENS EM \\ EMBALAGENS DE PRODUTOS ALIMENTÍCIOS PRONTOS E \\ SEMIPRONTOS: ILUSÃO OU ANALOGIA? \\ CONSUMER PERCEPTIONS OF IMAGES ON READY AND SEMI-READY \\ FOOD PRODUCT PACKAGING: ILLUSION OR ANALOGY?
}

\author{
Carla Arcoverde de Aguiar NEVES \\ Instituto Federal de Educação, Ciência e Tecnologia de Santa Catarina | IF-SC \\ carcoverde77@gmail.com \\ Rafael Burlani NEVES \\ Universidade do Vale do Itajaí - UNIVALI \\ rburlani@hotmail.com
}

\begin{abstract}
Resumo. Este artigo aborda a percepção do consumidor com relação às imagens de embalagens de produtos alimentícios prontos e semiprontos e qual sua avaliação diante da incongruência entre os dois universos: do real e da representação. Tem-se como metodologia para este trabalho a execução de levantamento bibliográfico e de uma investigação de campo dirigida a uma amostra da população dos consumidores de produtos alimentícios prontos e semiprontos, que residem na região metropolitana de Florianópolis (Brasil). Este trabalho identificou falhas na aplicação dessas imagens, destacando-se a distanciação da noção de realidade, o que define um cenário de frustração e inadequação na ótica do consumidor.
\end{abstract}

Palavras-chave: embalagem, imagem, consumidor, linguagem.

\begin{abstract}
This article approaches consumer perceptions towards images on ready and semi-ready food product packaging, as well as how they evaluate the incongruence among both universes: reality and its representation. The method for this paper is a combination of bibliographic review and field study directed towards a sample of consumers of ready and semi-ready food products residing in the metropolitan area around Florianopolis, Brazil. This study identified failures in image application with highlights to its distant notion of reality, which outlines a scenario of inadequacy and frustration from the consumers' point of view.
\end{abstract}

Keywords: Packaging, Image, Consumer, Language

\section{Introdução}

Este trabalho estabelece como objeto de estudo uma categoria de produtos de consumo que possui grande representatividade e relevância para seus usuários — a categoria de embalagens. As embalagens podem ser entendidas como relevantes, por cumprirem diversas funções, como as de caráter físico e estrutural (embalar, proteger e transportar), possibilitando, inclusive, em muitos casos, a tangibilidade de determinados produtos. E também de caráter simbólico, através de elementos gráficos (fontes, ilustrações, fotos, logotipos, cores) que podem formular uma intensa cadeia de significações e modos de percepção diferenciados para os seus consumidores. 
Por constituir-se nesta multiplicidade de componentes, o foco aqui se restringe somente a um desses elementos, as imagens - quer sejam ilustrativas, ou fotográficas - aplicadas a estes suportes midiáticos. Essa escolha se deu, por elas apresentarem forte poder de atração perante o consumidor e por contribuírem significativamente na construção do conceito que se faz dos produtos adquiridos.

Objetiva-se, portanto, demonstrar a percepção do consumidor com relação às imagens de embalagens de produtos alimentícios prontos e semiprontos, assim como o seu julgamento conexo com a veracidade de representação, entre a imagem e o objeto representado, após seu preparo.

Para se alcançar os objetivos aqui definidos e responder as questões levantadas, realizou-se uma investigação de campo do tipo quantitativa descritiva, com a aplicação de questionário, dirigida a uma amostra da população dos consumidores de produtos alimentícios prontos e semiprontos, que residem na região metropolitana de Florianópolis (Brasil) totalizando um número de 232 questionados.

\section{Revisão de Literatura}

\subsection{Imagem como Representação}

Para Aumont (2004), a representação é um processo pelo qual se estabelece um representante que, de forma limitada, tomará o lugar do que representa. Ela é ao mesmo tempo arbitrária, motivada e relacionada com a realidade. É arbitrária porque, neste processo de representação, a criação de um substituto vai se basear, por meio eventual, na existência de convenções socializadas. É motivada porque determinadas convenções são aprendidas com muita facilidade por todo indivíduo ou, dependendo da situação, nem precisam ser aprendidas. Por fim, está relacionada com a realidade através de dois níveis principais: psicoperceptivo e sócio-histórico.

Santaella e Nöth (2001) afirmam que o conceito de representação se encontra como eixo central da teoria da ciência cognitiva, a qual trata de temáticas variadas como a representação analógica, digital, proposicional, cognitiva, ou ainda de modo geral, representação mental. Já na semiótica geral, sua conceituação varia entre a apresentação e a imaginação, estendendo-se ainda a conceitos semióticos centrais como signo, veículo do signo, imagem ("representação imagética"), assim como significação e referência.

Vale destacar que a representação pública para Sperber equivale ao signo no sentido do representâmen peirciano, enquanto que a representação mental equivale ao 
interpretante sígnico. O próprio Peirce (2000, p. 61) diz que representar é “[...] estar numa tal relação como um outro que, para certos propósitos, é considerado por alguma mente como se fosse esse outro".

Segundo Litaiff (2002), para o pragmatismo do qual Peirce fazia parte, o conhecimento só é possível se houver relação entre o real e o pensamento, pois o real fornece as bases para os conceitos os quais, por sua vez, servem de subsídio para o saber e orientam as ações.

Neiva Jr (2002) salienta sua visão de relação da representação imagética com sua capacidade de referência, observando que este referencial é de caráter linguístico, portanto, não existe para ele possibilidade de se entender uma representação por imagens, sem recorrer aos atos da fala.

Sobre esta mesma temática, Aumont (2004, p. 248) expõe a noção de diegese, que é:

[...] uma construção imaginária, um mundo fictício que tem leis próprias mais ou menos parecidas com leis do mundo natural, ou pelo menos com a concepção, variável, que dele se tem. Toda construção diegética é determinada em grande parte por sua aceitabilidade social, logo por convenções, por códigos e pelos simbolismos em vigor numa sociedade.

Para Crépeau (1996) parte também de uma convenção, o poder de veracidade desta representação. Isso porque, para este autor, a representação se manifesta em um nível social, pelo qual os interlocutores chegam a um consenso a respeito dos elementos do mundo o que, por sua vez, exige um modelo de triangulação entre dois indivíduos e o objeto referente, estabelecendo assim, um contexto comunicacional. (LITAIFF, 2002) Percebe-se então, que a representação possui um caráter de substituição, atuando como mediadora, substituindo a coisa representada, pela própria forma de representação. A representação equipara-se ao seu substituído, podendo se vislumbrar por meio de uma ilusão, ou simulacro, por exemplo.

De acordo com Aumont (2004), a ilusão mais significativa é aquela produzida deliberadamente em uma imagem, porque funcionará bem, de acordo com as condições culturais e sociais nas quais ocorre. $\mathrm{O}$ autor ressalta, ainda, que a ilusão será mais eficaz se for bem traduzida nas formas de imagens socialmente admitidas.

Outras noções essenciais para se entender a representação são: a questão da analogia, semelhança, realismo e denotação. Sobre a analogia, Aumont (2004) coloca que, por se ter um hábito bastante comum de se ver, quase sempre, imagens fortemente 
analógicas, perpetua-se o costume de se apreciar mal este fenômeno da analogia, relacionando-o de modo irrefletido a um tipo de ideal que é a semelhança perfeita entre a imagem e seu modelo. Sobre isso, Neiva Jr (2002) ressalta que a semelhança não garante a representatividade, porque esta pode ser somente uma suposta familiaridade, as réplicas dependem de convenções que, por estarem consolidadas socialmente, são tratadas como naturais. $\mathrm{O}$ autor lembra que, antes de o indivíduo se extasiar pela capacidade substitutiva de uma imagem, deveria se atentar para o que ela realmente é, ou seja, uma disposição de formas no espaço. Os elementos que a constituem não deveriam ser percebidos como cópias do real, porém, ele lembra que a cultura ocidental valoriza de forma extremada a imitação.

Aumont (2004) esclarece que Mímesis é uma palavra grega que significa imitação e tem o mesmo sentido de analogia, sendo adotada para designar o ideal da semelhança absoluta. A partir das referências de Bazin (1945), Aumont (2004) diz que com o surgimento da fotografia, a pintura, que até então tinha esta obrigação, pode libertar-se da semelhança, satisfazendo assim mecanicamente o desejo de ilusão. Para ele, a imagem fotográfica tem uma “[...] essência, que é ser uma "alucinação verdadeira", "embalsamar" e "revelar" o real em todos os seus aspectos, inclusive temporais. É, pois, a encarnação de uma semelhança ideal [...].” (BAZIN, 1945 apud AUMONT, 2004, p.200).

Vale destacar outro ponto de vista com relação à noção de realidade. Para tanto, expõe-se a ideia de Crépeau (1997) que defende que o real não se vincula necessariamente à apreensão direta, pois o real é compreendido por meio da representação de uma representação e faz parte de representações coletivas que situam o indivíduo fora da natureza e exigem interações entre domínios humanos e não humanos. (LITAIFF, 2002).

É fundamental não confundir as noções de ilusão, de representação e de realismo.

A representação é o fenômeno mais geral, o que permite ao espectador ver "por delegação" uma realidade ausente, que the é oferecida sob forma de um substituto. A ilusão é um fenômeno perceptivo e psicológico, o qual, às vezes, em determinadas condições psicológicas e culturais bem definidas, é provocado pela representação. $\mathrm{O}$ realismo, enfim, é um conjunto de regras sociais, com vistas a gerir a relação entre a representação e o real de modo satisfatório para a sociedade que formula essas regras. 
Mais que tudo, é fundamental lembrar-se de que realismo e ilusão não podem ser implicados mutuamente de maneira automática. (AUMONT, 2004, p.103).

\section{Metodologia}

O objetivo deste trabalho é demonstrar a percepção do consumidor com relação às imagens de embalagens de produtos alimentícios prontos e semiprontos, assim como o seu julgamento conexo com a veracidade de representação, entre a imagem e o objeto representado, após seu preparo.

A pesquisa de campo realizada com os consumidores visou proporcionar um estudo sobre o modo como vem sendo tratado o tema pesquisado, em uma realidade prática, confirmando ou não, os resultados obtidos, a partir da pesquisa bibliográfica (MINAYO, 1994).

Para tanto, a abordagem adotada foi do tipo pesquisa quantitativa descritiva, consolidada com a aplicação de questionários dirigidos a uma amostra da população (ou universo) dos consumidores de produtos alimentícios prontos e semiprontos, que residem na região metropolitana de Florianópolis.

Portanto, dentro do universo estabelecido para a pesquisa, esta porção foi apreendida conforme seu surgimento até que se alcançasse o número determinado para a amostragem, que está pautado na fórmula definida por Martins (2002), e auxilia na determinação do tamanho da amostra para estimar a proporção de uma população (universo) infinita, que é o caso específico dos consumidores de produtos alimentícios prontos e semiprontos, da região metropolitana de Florianópolis.

Fórmula: $n=\frac{z^{2} \cdot p \cdot q}{e^{2}}$, onde:

$\mathrm{z}=1,96$ - valor da distribuição normal padrão. Para o nível de confiança for 95\% (geralmente usado);

$\mathrm{p}=$ proporção de respondentes para opção "sim" $(\mathrm{p}=0,5)$

$\mathrm{q}=$ proporção de respondentes para opção "não" $(\mathrm{q}=0,5)$

$\mathrm{e}=$ erro amostral.

$\mathrm{n}=$ tamanho da amostra aleatória simples a ser selecionada da população.

Dentro desses parâmetros, o tamanho da amostra seria de 385 consumidores para serem questionados, com uma margem de erro de $5 \%$, porém, devido à limitação de 
tempo e dos objetivos do trabalho, esse número passou para 232 (duzentos e trinta e dois) consumidores.

\section{Resultados e discussão dos dados}

Para a demonstração dos dados alcançados com esta pesquisa, evidenciaram-se somente aqueles dados mais significativos, que possuem relação direta com a percepção do consumidor, com relação às imagens de embalagens de produtos alimentícios prontos e semiprontos.

Sendo assim, um primeiro dado que se levantou aqui foi o fato de que do total de entrevistados, $56 \%$ sempre se atentam para o rótulo/embalagem, $41 \%$ quase sempre, e 3\% nunca. Esses dados são relevantes, uma vez que apontam que as embalagens e, consequentemente, todo o seu caráter informacional, de ordem verbal ou não-verbal, atraem a atenção dos consumidores e acionam suas percepções.

A partir disso, percebe-se que os objetivos comunicacionais são bem estabelecidos, conforme o que apontam Niemeyer (2003) e Berlo, (1991), os quais salientam que, para obter a atenção e modificação de uma conduta do receptor, nesse caso, o consumidor, deve-se manipular a mensagem e definir com exatidão o "a quem" e o "como" afetar.

Outra questão relevante é sobre quais os elementos chamam a atenção do consumidor nesta percepção do rótulo/embalagem. Pode-se destacar que, dos entrevistados, $31 \%$ optaram pelo elemento imagens como sendo aquele que mais chama a sua atenção, 26\%, informações escritas, 23\%, cores, 14\%, logotipos e $6 \%$, outros elementos.

Portanto, dentre as respostas apontadas, ressalta-se que a maioria $(68 \%$, somando-se os que optaram por imagens, cores e logotipia) se preocupa em olhar o rótulo da embalagem e seus elementos gráficos principais, ficando em segundo plano, a relevância das informações escritas. Observa-se, ainda, a significativa quantidade de pessoas $(31 \%)$ que apontaram ser a imagem o elemento de maior atração existente nas embalagens.

Sobre essas questões, pode-se destacar o entendimento de Featherstone (1995, p.33), sobre a definição de mercadoria-signo, que veio justamente estabelecer um deslocamento: “[...] da produção para a reprodução, para a reduplicação infinita de signos, imagens e simulações por meio da mídia, abolindo a distinção entre imagem e realidade." O autor alega ainda, que, na sociedade pós-moderna, a estetização tornou-se 
ponto referencial e os processos industriais que viabilizam esta dinâmica reprodutiva são altamente valorizados. Sendo assim, áreas como a publicidade, design industrial e design gráfico, que se apropriam das embalagens como objetos projetuais, consolidamse cada vez mais.

Vale complementar aqui que, para Jameson (2002), dentro desta noção de reprodutibilidade e de valorização da imagem, os produtos se destacam e se hierarquizam principalmente por causa de sua tecnologia de reprodução e veiculação na mídia. Sendo assim, as próprias embalagens, com seus recursos de reprodução e destaque imagético, tornaram-se objetos de desejo e consumo.

$\mathrm{Na}$ questão sobre a percepção das imagens (ilustrações ou fotografias) vinculadas nas embalagens como verdadeiras, pode-se destacar que $27 \%$ percebem, às vezes, as imagens vinculadas nas embalagens como verdadeiras, 32\% não percebem como verdadeiras e $41 \%$ percebem como verídicas.

Somando-se os que percebem às vezes $(27 \%)$ com os que não percebem como verdadeiras (32\%), tem-se uma maioria de 59\% fato que demonstra que, para o consumidor de modo geral, as imagens ali empregues levam a uma falsa ideia da realidade.

A partir dessa ideia, Aumont (2004) destaca que a principal razão para a produção de imagens é justamente fazer com que elas tenham um papel de mediador, entre o espectador e a realidade. Sendo assim, tem-se uma contradição no uso desse tipo de recurso nas embalagens, pois as imagens fogem deste objetivo central que é mediar a realidade.

Sobre os comentários expostos acima, percebe-se que grande parte dos consumidores vê as imagens aplicadas às embalagens como muito distantes da realidade que representam, neste caso, o alimento após o preparo. A grande maioria aponta, ainda, que as imagens são sempre maiores, mais belas e mais atrativas do que o próprio alimento. Tais consumidores consideram a existência de um processo de manipulação dessas imagens, que trabalha sempre em prol da exacerbação de predicativos não encontrados na realidade.

Considerando-se ainda os três níveis relacionais entre mundo e imagem, estabelecidos por Aumont (2004), percebe-se que no caso das embalagens, as imagens enquadram-se em dois níveis, que são: o modo epistêmico, o qual indica que a imagem carrega consigo informações (visuais) sobre o mundo, possibilitando assim o conhecimento sobre este; e o modo estético, o qual preconiza que a imagem tem a 
função principal de agradar a seu espectador e oferecer-lhe sensações (aisthésis) específicas. Dentro dessa panorâmica, nota-se, pelo que foi apontado pelos consumidores, que o modo epistêmico não é aplicado eficazmente, desvirtuando a relação entre mundo (realidade) e imagem. Porém, o modo estético é altamente e indevidamente trabalhado, fazendo com que o consumidor se sinta lesado, ao não identificar essa relação direta entre mundo e imagem e perceber, por outro lado, a exaltação de efeitos estéticos que só distanciam ainda mais esta relação.

Em um aspecto que complementa a anterior, a qual questiona se o consumidor opina que as imagens (ilustrações ou fotografias) vinculadas nas embalagens reproduzem a realidade de preparo dos alimentos, chegou-se ao resultado de que $70 \%$ dos consumidores não pensam que as imagens reproduzem a realidade de preparo dos alimentos, enquanto que $30 \%$ acreditam que sim.

Essa diferença tão evidente vem ressaltar mais uma incongruência entre estas relações: a imagem mental que o consumidor obviamente projeta do alimento, após o preparo, é vinculada à imagem que ele percebe nas embalagens. Não havendo esta associação, ele assume uma postura de descontentamento e frustração, diante do que ele esperava, em termos de resultado final de seu consumo.

Com um percentual tão alto de pessoas que não acham que a imagem corresponde à realidade $(70 \%)$, as empresas fabricantes poderiam repensar sobre a produção das imagens nas embalagens de produtos alimentícios, com o intuito de fidelizar e atender a expectativa destes consumidores, bem como captar novos clientes.

O consumo está relacionado diretamente com a publicidade e o design, áreas que dão forma ao processo de persuasão e sedução do consumidor e, portanto, os conduzem à compra. Sobre essa manipulação e distorção da realidade das imagens publicitárias, Neiva Jr (2002, p. 71) afirma que “[...] a imagem publicitária constrói, com requinte de artificialidade, a figuração da cena que será apresentada sedutoramente ao consumidor como condição de felicidade." Referenciando-se essa visão, nota-se que o objetivo central dessas áreas de atuação é justamente manipular esses elementos para obter o máximo de possibilidade de consumo, porém, o efeito que se está dando em específico às imagens das embalagens é contrário ao que se espera, pois os consumidores percebem essa artificialidade construída e se sentem lesados, enganados e decepcionados com o resultado final.

Buscando-se um aprofundamento a respeito da opinião sobre as imagens (ilustrações ou fotografias) aplicadas nas embalagens, destaca-se que dos entrevistados, 
48\% opinam que as imagens promovem uma falsa percepção do prato pronto, $31 \%$ alegam que facilitam a compreensão do que contém a embalagem, e $21 \%$ que acentuam os predicativos dos pratos. Vale ressaltar, ainda, que não houve nenhuma resposta para a opção em que as imagens retratam fielmente o alimento após o preparo. Se somar aqueles que apontam as imagens como promotoras de uma falsa percepção e que estas acentuam os predicativos dos pratos $(69 \%)$, corrobora-se a ideia já trabalhada de insatisfação diante da manipulação destas imagens e da exacerbação das qualidades que não são percebidas após o preparo.

Essa falsa percepção pode ser entendida como um processo ilusório, pois para Aumont (2004, p. 96) a ilusão é “[...] um erro de percepção, uma confusão total e errônea entre a imagem e outra coisa que não seja esta imagem.” Sendo assim, podemse perceber traços de ilusão justamente porque se tenta trabalhar com uma aproximação da realidade que, por fim, não é a própria realidade e sim, uma simulação desta.

Com o intuito de se compreender o alcance do resultado de preparo demonstrado nas embalagens, através das imagens, pode-se destacar que, dos entrevistados, 47\% (109) alcançam, às vezes, essa similitude do resultado de preparo com o que é demonstrado nas imagens, 39\% não alcançam, e 14\% alcançam.

Percebe-se que a maioria das pessoas ( $86 \%$ ) não atinge geralmente o resultado desejado e simulado por meio das imagens das embalagens, o que, mais uma vez, ressalta a noção de que não há congruência entre estes dois universos: o do real e o da representação. Neste caso em específico, sabe-se que o produto, congelado ou resfriado, não tem como se relacionar com a realidade, porém à medida que o direcionam para preparo final, deveria ter essa correspondência com sua representação, ou seja, com a imagem aplicada à embalagem.

Baseada na ideia de representação de Peirce, Ferrara (2002, p. 7) alega que essa representação "[...] é um simulacro do mundo a partir de um sistema de signos". A partir disso, entende-se que a representação deve ter uma similitude com a realidade que ela retrata, deve, no mínimo, aplicar vestígios qualitativos ou indiciais de relação com essa realidade.

A maioria das embalagens de produtos alimentícios prontos e semiprontos vem com algum tipo de inscrição, como por exemplo, "imagem meramente ilustrativa", que é utilizada com o objetivo de amenizar os efeitos de uma disparidade entre imagem e produto final após o preparo. Sendo assim, achou-se pertinente questionar sobre a suficiência dessa inscrição para validar alguma oposição entre a imagem e o resultado 
final do preparo. Dos entrevistados, 55\% acham que o aviso imagem "meramente ilustrativa" não valida alguma oposição entre a imagem e o resultado final do produto, e $45 \%$ acham que o estabelecimento de tal informação é o suficiente. Vê-se por meio disso, que ainda há uma grande parcela (55\%) de consumidores que, mesmo sendo informados sobre uma possível dissociação entre a representação e a realidade, não se sentem confortáveis e percebem essa tentativa de convencimento como não suficiente para validar tal disparidade.

Torna-se relevante destacar o fato de que alguns autores adotam o princípio da imagem como um meio direto de expressão do mundo, sem a necessidade da vinculação com a linguagem verbal. Sobre isso Aumont (2004, p. 249) cita Munier (1963):

[...] a imagem substitui a forma escrita por um modo de expressão global, de grande poder de sugestão, e inverte a relação tradicional do homem com as coisas: o mundo não é mais nomeado, ele próprio se diz em sua repetição pura e simples, torna-se seu próprio enunciado.

A partir disso, preconiza-se que a melhor forma de veiculação da mensagem sobre a realidade do produto, é por meio da própria imagem, ou seja, esta representa por si só a verdade sobre esses produtos, portanto, deve ser adequadamente aplicada para não repassar uma ideia equivocada aos consumidores.

Sobre o possível sentimento de frustração nesta relação, questionou-se se o consumidor já se sentiu frustrado ao comparar o resultado final do produto a ser consumido com a imagem vinculada na embalagem. Dos entrevistados, $74 \%$ já se frustraram com o resultado final do produto em relação à imagem da embalagem, e $26 \%$ não se frustraram. Sendo assim, percebe-se um alto índice de consumidores que desenvolveu um sentimento de descontentamento com relação a esse objeto midiático e seus elementos constituintes, principalmente as imagens que repassam uma falsa noção do que é produto.

Isso está bastante atrelado ao fato das imagens serem frequentemente manipuladas, com o intuito de se potencializarem os atributos dos alimentos embalados e, sobre isso, Anandpara (2014) comenta que, ultimamente, a manipulação da imagem digital se proliferou e seu uso de faz constante em várias situações e esferas, como na indústria da moda, propaganda, revistas científicas e outros. Sendo assim, a modificação de imagens para fins indevidos tem sido bastante comum, provocando um problema social. 
Finalmente, questionou-se sobre a preferência de se ter na embalagem uma imagem fiel do alimento preparado. Dos entrevistados, 69\% dizem ter preferência por uma imagem fiel do alimento preparado na embalagem, enquanto $31 \%$ dizem que não têm essa preferência. Mais uma vez verifica-se que a maioria dos questionados gostaria de perceber as imagens aplicadas às embalagens, no sentido de sua associação à realidade, portanto, imagens que empregassem preceitos de analogia, imitação e realismo.

Conotter et al. (2014) afirmam que, de modo geral, cria-se uma expectativa de que as imagens sejam um reflexo honesto da realidade. Porém, essa prerrogativa é prejudicada pela aplicação das novas tecnologias de edição de imagens, que geram uma maior facilidade na manipulação e distorção desses elementos.

Esta compreensão promove um comportamento diferenciado por parte do consumidor, que passa a confiar e crer nas marcas e produtos que se utilizam do recurso da analogia. Carlson; O'Cass (2011) trazem um conceito interessante que versa sobre este aspecto, que é o da Teoria da Congruência, pela qual o comportamento do consumidor é redirecionado pela congruência resultante de uma comparação psicológica envolvendo a imagem e os objetos por ela representados.

\section{Considerações Finais}

A proposta deste trabalho foi demonstrar a percepção do consumidor com relação às imagens de embalagens de produtos alimentícios prontos e semiprontos, assim como o seu julgamento sobre o teor de veracidade aplicado a tais elementos. Isto pôde ser realizado por meio do levantamento teórico, que estudou a percepção humana, em termos fisiológicos e psicológicos, além do estabelecimento de conceitos essenciais para o entendimento do universo que constitui o consumo, as mídias e as imagens. Os resultados puderam ser adquiridos por meio da pesquisa de campo, que mostrou com efetividade a visão e o comportamento dos consumidores diante de cenas.

Percebeu-se, a partir dos dados coletados, que o uso de imagens é essencial para tal objeto midiático, não somente pelo fato de os consumidores identificarem esses elementos gráficos como relevantes, mas principalmente porque se puderam levantar diretrizes teóricas que indicam que este tipo de informação auxilia no processo de comunicação, dinamizando-o e facilitando a interpretação das mensagens expostas.

Destaca-se, aqui, a contribuição deste trabalho, que identificou uma falha na aplicação dessas imagens. Sugere-se, pautando-se nas duas pesquisas - de campo e 
bibliográfica - que a orientação para a aplicação dessas imagens deva ser no sentido de se trabalhar com a "verdade", com o "retrato da realidade", com a analogia.

Uma atitude comum no desenvolvimento destes objetos comunicacionais estabelece-se como uma possível postura antiética. Faz-se aí uma observação, atribuindo meia culpa aos empresários e também aos profissionais da publicidade e design. Ambos trabalham com o objetivo de aumentar vendas e, para isso, aplicam elementos gráficos, principalmente as imagens, que ludibriam e iludem os consumidores. Há uma supervalorização de imagens sobrepujando a realidade, desvinculando-se do referencial do real e conduzindo à ilusão. Porém, o perigo de tal ato é que a referência da realidade existe, ela está na concretização do preparo do alimento. É nesse momento que a frustração, por parte do consumidor, se configura, por não existir a congruência entre representação e o mundo (realidade).

A disparidade entre estes dois lados, pode levar o indivíduo a se sentir enganado e lesado, contribuindo para a posterior rejeição do produto em uma próxima compra. Isto se a pessoa que se sentiu lesada não achar por bem requisitar seus direitos de cidadão e buscar soluções por meio de ações judiciais, ou recorrências a órgãos de proteção ao consumidor (PROCON). Esse quadro estabelece, a longo prazo, principalmente diante de uma nova consciência, com relação aos direitos dos consumidores e cidadãos, um prejuízo também às empresas que, ao contrário de angariarem mais apreciadores, ou mantê-los, poderão perdê-los, sucumbindo, assim, diante de concorrentes que possam adotar posturas mais coerentes e corretas.

Ressalta-se, portanto, que os profissionais que trabalham com a manipulação destas imagens, deveriam saber quais as interferências do uso inadequado destas em seus projetos e, se preciso fosse, deveriam mudar esses paradigmas e agregar ao mercado uma nova postura de atuação frente a esses objetos midiáticos.

Vislumbra-se, para tal situação, uma possibilidade de caminho a ser adotado, que é a aplicação da representação por meio de analogia, realismo ou mimese, ou seja, fazer com que se tenha perfeição ou elevada proximidade de comparação entre o que representa e aquilo que é representado. Para tanto, sugerem-se duas possibilidades de atuação: diminuição dos efeitos e manipulações aplicados às imagens, aproximando-as do alimento preparado, ou melhora da qualidade desses alimentos, atribuindo-lhes, consequentemente, uma boa estética após o preparo, o que proporcionará um registro sem maquiagem desses produtos, podendo depois ser retratados nas embalagens. Essas opções de atuação fariam com que o consumidor identificasse com certidão e 
veracidade qual produto estaria consumindo e preparando, sem nenhum prejuízo, ou frustração.

Considerando que os objetivos do artigo foram alcançados, percebe-se que a pesquisa mostrou sua relevância ao trazer diferentes visões e demandas sobre objetos midiáticos e sobre a aplicação imagética, abrindo-se, assim, uma nova esfera de atuação para os profissionais da área, além de trazer uma significativa contribuição teórica para a problematização das questões aqui apontadas e para o mundo acadêmico, que pouco possui, em termos de dados que relacionem estas áreas, promovendo, assim, um aprofundamento maior das questões aqui estudadas.

\section{Referências}

ANANDPARA, D. An assessment of digital image forgery detection techniques. Industrial Scienc. Vol.1, Issue.4, April, 2014.

AUMONT, J. A imagem. Campinas: Papirus, 2004.

BERLO, D. K. O processo da comunicação: introdução à teoria e a prática. 7.ed. São Paulo: Martins Fontes, 1991.

CARLSON, J.; O'CASS, A. Managing web site performance taking account of the contingency role of branding in multi-channel retailing. Journal of Consumer Marketing, 28/7, p.524-531, 2011.

CONOTTER, V. et al. Assessing the Impact of Image Manipulation on Users' Perceptions of Deception. Human Vision and Electronic Imaging XIX, Proc. of SPIEIS\&T Electronic Imaging, Proc. of SPIE Vol. 9014, 90140Y, 2014.

FEATHERSTONE, M. Cultura de consumo e pós-modernismo. São Paulo: Studio Nobel, 1995.

FERRARA, L. D’A. Leitura sem palavras. 4.ed. São Paulo: Ática, 2002.

JAMESON, F. Pós-modernismo: a lógica cultural do capitalismo tardio. 4 ed. São Paulo: Ática, 2002.

LITAIFF, A. Antropologia e linguagem: uma abordagem neo-pragmatista. Linguagem em (Dis)curso. Tubarão, v. 3, n. 1, p. 225-272, jul./dez. 2002.

MARTINS, G. A. Estatística geral e aplicada. 2. ed. São Paulo: Atlas, 2002.

MINAYO, M. C. S. Pesquisa social: teoria, método e criatividade. 7. ed. Petrópolis: Vozes, 1994.

NEIVA JR., E. A imagem. 2.ed. São Paulo: Ática, 2002.

NIEMEYER, L. Elementos de semiótica aplicados ao design. Rio de Janeiro: 2AB, 2003.

PEIRCE, C. S. Semiótica: estudos. 3.ed. São Paulo: Perspectiva, 2000.

SANTAELLA, L.; NÖTH, W. Imagem: cognição, semiótica, mídia. 3.ed. São Paulo: Ed. Iluminuras Ltda., 2001. 